\title{
Subdural infusion of dexamethasone inhibits leukomyelitis after acute spinal cord injury in a rat model
}

\author{
Jacek M. Kwiecien ${ }^{1}$, Bozena Jarosz ${ }^{2}$, Lucia Machova Urdzikova ${ }^{3}$, Radoslaw Rola ${ }^{2}$, Wojciech Dabrowski ${ }^{4}$ \\ ${ }^{1}$ Department of Pathology and Molecular Medicine, Michael G. deGroote School of Medicine, McMaster University, Hamilton, Canada, \\ ${ }^{2}$ Department of Neurosurgery and Paediatric Neurosurgery, Medical University of Lublin, Lublin, Poland, ${ }^{3}$ Department of Stem Cells \\ and Tissue Repair, Institute of Experimental Medicine, Academy of Sciences of the Czech Republic, Prague, Czech Republic, \\ ${ }^{4}$ Department of Anaesthesiology and Intensive Therapy, Medical University of Lublin, Lublin, Poland
}

\begin{abstract}
Trauma in spinal cord injury often results in massive damage to the white matter and in damage to myelin that results in a severe phagocyte-rich infiltration apparently directed at removing immunologically toxic myelin debris. In the epidural balloon crush injury to the rat cranial thoracic spinal cord, the dorsal column was crushed, which at one week post-op resulted in its obliteration by a severe infiltration by a virtually pure population of macrophages that internalized all damaged myelin. A week-long subdural infusion of dexamethasone, a stable synthetic corticosteroid, resulted in remarkable inhibition of the macrophage infiltration of the crush cavity and in the lack of removal of myelin debris by phagocytosis. In this study we demonstrated that spinal cord injury results in a severe inflammatory response directed at massively damaged myelin, and we inhibited this response with a subdural infusion of a powerful anti-inflammatory drug, dexamethasone.
\end{abstract}

Key words: spinal cord injury, leukomyelitis, macrophages, subdural infusion, dexamethasone.

\section{Introduction}

Acute damage to the tissue in spinal cord injury $(\mathrm{SCl})$ results in mechanical disruption, haemorrhages and ischaemia, which after $48 \mathrm{~h}$ (Kwiecien, unpublished) are followed by a severe inflammatory infiltration [57] that soon becomes directed primarily against damaged myelin and is primarily represented by macrophages $[11,12,27,49,58]$. This secondary inflammation in the spinal cord white matter is known as leukomyelitis, and is a well-recognized pathological process whose mechanisms are not well understood. Neuropathological evidence indicates that leukomyelitis is a chronic, tissue destructive process, probably sustained by a mechanism of a vicious cycle where massively damaged myelin acts in a potently pro-inflammatory fashion [33], attracting a large number of blood-borne macrophages which when activated, phagocytise damaged myelin and, in the process release a variety of pro-inflammatory factors that cause additional tissue damage involving more myelin damage and macrophage chemotaxis $[3,18,19,29,30,39,48,50,56,60]$. Although actively expanding leukomyelitis in the rat 
runs well beyond 2 months [33], its total duration is not known in experimental animals and in human patients, but this severe inflammatory process is self-limiting, indicating unknown anti-inflammatory factors in the surrounding tissue. Since the long duration of leukomyelitis is associated with an expanding volume of irreversibly destroyed tissue of the spinal cord [18] and with progressive loss of neurologic function, the inhibition of this process was attempted in this study.

Methylprednisolone succinate (MPS), a powerful synthetic glucocorticoid derivative, is currently the only approved treatment of spinal cord injury patients. In the standard treatment, an $\mathrm{SCl}$ patient follows the National Acute Spinal Cord Injury Study (NASCIS) recommendation and is given an intravenous bolus injection of $30 \mathrm{mg} / \mathrm{kg}$ body weight (b.w.) of MPS that is followed by 24-48 hours of intravenous infusion at $5.4 \mathrm{mg} / \mathrm{kg}$ b.w./hour [6,7]. This treatment is widely considered as not successful in improving the outcome in the treated $\mathrm{SCl}$ patients versus non-treated individuals $[17,45]$. Severe side effects related to very high doses of MPS have been described in human patients; they include wound infection, pneumonia, sepsis and steroid myopathy and add to the problematic therapeutic value of this treatment [40]. In a study performed on cats, a $30 \mathrm{mg} /$ $\mathrm{kg}$ b.w. intravenous (i.v.) bolus of MPS was found to translate into $1.3 \mu \mathrm{g} / \mathrm{g}$ (or $0.004 \%$ of total injected) of wet tissue of the spinal cord [8]. The authors of this study determined that the half life of MPS in the spinal cord tissue was $3 \mathrm{~h}$ and recommended a $15 \mathrm{mg} /$ kg b.w. injection i.v. every 3 hours to maintain this tissue level. These data indicate that intravenous administration of large quantities of MPS may not translate into its therapeutic effectiveness in the $\mathrm{SCl}$ at the tissue level. In addition, since leukomyelitis is a chronic inflammatory process, for an anti-inflammatory therapy to be effective, it should likely be administered in a sustained fashion, well beyond a single intraperitoneal (i.p.) injection of $30 \mathrm{mg} /$ kg b.w. [32,42,53-55], or multiple i.p. injections over $48 \mathrm{~h}$ [24], or single intravenous (i.v.) injection of $30 \mathrm{mg} / \mathrm{kg}$ b.w. $[13,15,23,28,41]$ or multiple i.v. injections within $24 \mathrm{~h}$ [43], or $30 \mathrm{mg} / \mathrm{kg}$ b.w. bolus i.v. followed by maintenance $5.4 \mathrm{mg} / \mathrm{kg}$ b.w. per hour for $24 \mathrm{~h}$ [25]. A short-term intrathecal administration [62] as performed in some experiments on $\mathrm{SCl}$ rats or a single i.v. injection of $30 \mathrm{mg} / \mathrm{kg}$ b.w. [64] or a bolus i.v. injection of $30 \mathrm{mg} / \mathrm{kg}$ b.w. followed by i.v. injections of $5.4 \mathrm{mg} / \mathrm{kg}$ b.w. every $2.5 \mathrm{~h}$ [37] in rabbit models of $\mathrm{SCl}$, or single or multiple doses of 15$60 \mathrm{mg} / \mathrm{kg}$ b.w. i.v. in a cat model of SCl [1,9], were also attempted. The NASCIS 24-48-hour intravenous protocol is available to human patients $[6,7,63]$, but it is not considered efficacious.

In the present study we adopted an epidural spinal cord injury method with a crush effected by a temporarily inflated balloon [61] to create an injury and initiate leukomyelitis. We infused the crush lesion subdurally with dexamethasone, a stable and more powerful substitute for MPS, delivered over a period of 1 week, which resulted in a virtually absent infiltration by macrophages that we interpret as inhibition of leukomyelitis.

\section{Material and methods}

Experiments on rats were conducted at the Central Animal Facility, McMaster University, after approval by the Animal Research Ethics Board according to the guidelines by the Canadian Council on Animal Care.

\section{Balloon compression spinal injury}

A total of 13 mature Long Evans rats of both sexes were induced and maintained under isoflurane anaesthesia. Balloon crush injury was adopted from Vanicky et al. [61,62]. Laminectomy was performed over the lumbar region of the spinal cord and a $3 \mathrm{~F}$ embolectomy catheter (ZTS Hagmed, Poland) was inserted epidurally over the dorsal spinal cord to place the balloon in the rostral thoracic segment of the spinal cord. The sleeve of the catheter was filled with saline, and the balloon was inflated with $0.2 \mathrm{ml}$ of saline using a Hamilton syringe (VWR International) for $5 \mathrm{~s}$. After the compression evidenced by sudden movement of the hind legs, the balloon was deflated and the catheter carefully removed.

\section{Subdural infusion}

Immediately after the balloon crush, in the laminectomy site in the lumbar spine the dura was cut with a 25 gauge needle and a rat intrathecal catheter (Alzet, Durect Corporation, Cupertino, CA) was carefully inserted into the subdural space over the dorsal spinal cord to approximate the end of the catheter with the site of the balloon crush. After the steel wire was removed from the catheter, the free end was attached to a $2 \mathrm{ml}$ osmotic pump with infu- 
sion time of 1 week (Alzet) that was pre-loaded with $2 \mathrm{ml}$ of dexamethasone (Dexamethasone 2, $2 \mathrm{mg}$ / $\mathrm{ml}$, Vetoquinol N-A. Inc, Lavartrie, Quebec, Canada) in 5 rats (dexamethasone treatment group, $n=5$ ) or $2 \mathrm{ml}$ of phosphate buffered saline (PBS) $\mathrm{pH} 7.2$ in 5 rats (control treatment group, $n=5$ ). The attached pump was placed subcutaneously on the flank of the rat. The surgery rats were injected subcutaneously with $5 \mathrm{ml}$ of saline and $0.3 \mathrm{ml}$ of ketoprofen $(10 \mathrm{mg} /$ ml, Anafen, Merial Canada, Inc., Baie d'Urfe, Quebec, Canada) for analgesia prior to recovery from anaesthesia. The injections of analgesic were repeated once daily for 2 more days, and administration of saline was performed 1-2 times daily as indicated by the hydration status. Three additional rats were subjected to the balloon crush and perfused at $2 \mathrm{~h}$ post-surgery to serve as acute controls.

\section{Clinical observations}

All 13 rats with the balloon crush injury recovered well and had marked paresis or complete paralysis of the hind end throughout the 1 week of survival. Rats treated with dexamethasone were doing progressively poorly after post-op day 4 . They were lethargic, dehydrated, the food intake was markedly reduced or nil, and the body condition was deteriorated. Rats treated with PBS remained in good health except for motor neurologic deficits. At post-op day 6 , open field behavioural testing was attempted on the rats, but it was deemed inconclusive due to pronounced weakness in dexamethasone-treated rats.

\section{Perfusions}

At post-op day 7, the surgery rats were overdosed with 100 mg/kg b.w. sodium barbital (Ceva, France), the chest was opened and 100 IU sodium heparin intracardiac injection was administered. The blood was washed out by lactated Ringer's solution (Baxter, Canada) via the left cardiac ventricle with the outflow created by cutting the right heart auricle [34]. The animals were perfusion-fixed in $10 \%$ buffered formalin, carcasses post-fixed at $4^{\circ} \mathrm{C}$ for $1-3$ hours and the spinal cord removed carefully and post-fixed in $10 \%$ formalin. Other routine tissues - the brain, mandibular salivary glands, thyroid glands, trachea, oesophagus, lung, heart, diaphragm, liver, spleen, kidney, pancreas, duodenum, caecum, colon, testis, epididymis, sexual glands, ovary, uterus, cervix and urinary bladder - were also sampled for histological analysis.

\section{Histology, immunohistochemistry}

The length of the spinal cord was sectioned transversely into $2 \mathrm{~mm}$ thick segments with the cranial face placed down in the tissue cassette. The tissues were treated by raising concentrations of ethyl alcohol and xylene, embedded in paraffin, cut $4 \mu \mathrm{m}$ thick and mounted on glass slides. Histochemical stains used included the routine haematoxylin and eosin (H\&E) stain, periodic acid-Schiff (PAS) to stain intracellular carbohydrates indicative of active phagocytosis [59] and Luxol fast blue (LFB) for myelin [59]. For immune stains, the glass-mounted sections were heated at $58^{\circ} \mathrm{C}$ overnight and deparaffinised in a Target Retrieval Solution, $\mathrm{pH}$ buffer (DAKO) at $97^{\circ} \mathrm{C}$ for 20 min in a DAKO PT Link Pre-Treatment Module for Tissue Specimens PT101 apparatus. Antibodies against the CD68 antigen and against the glial fibrillary acidic protein (GFAP) were obtained from DAKO Corp., were applied at a 1 : 50 dilution, and the positive reaction was visualized with DAKO EnVision+System-HRP (DAB+). The histological analysis was performed under a Nikon Eclipse 50i microscope and the abnormalities in the spinal cord and in other tissues photographed.

\section{Results \\ Clinical observations}

All rats recovered well from the surgery and had hind end paralysis. Some of the rats developed paralysis of the urinary bladder requiring manual expression of urine from a distended bladder 3-4 times a day. Although the untreated rats did well until the end of the study, rats treated with dexamethasone did poorly after day 4 post-op and were treated with subcutaneous saline $10 \mathrm{ml}, 1-2$ times a day until the sacrifice.

Although open field testing of the rats was attempted at post-op day 6, it was inconclusive, since the dexamethasone rats were remarkably weak and the motor function could not be assessed in relation to the spinal cord injury.

\section{Histology, immunohistochemistry}

In rats perfused 2 hours after the balloon crush surgery there was a tear of a large proportion of 
the dorsal column (Fig. 1) resulting in its separation from the surrounding tissue of the spinal cord. The separation contained discontinuous haemorrhages, but there was no evidence of active demyelination (Fig. 1B,E) or of infiltration by phagocytic cells (Fig. 1C,F).

In untreated rats at 1 week post-op the dorsal column was obliterated by a severe inflammatory exudate directly connected with the subdural space (Fig. 2A-C) composed predominantly of mononuclear cells containing an oval or round nucleus surrounded by abundant, often microvacuolated cytoplasm (Fig. 2D) staining positively with LFB (Fig. 2E) for internalized myelin debris and often staining positively with PAS (Fig. 2F), which indicates active phagocytosis [59]. Free, un-phagocytized red blood cells and LFB-positive debris were not apparent in the inflammatory exudate (Fig. 2D-E). The phagocytic cells were interpreted as macrophages, some of which stained or stained weakly with anti-CD68 antibody (Fig. 2G) even though this antibody labelled well numerous monocytes in the lumen of blood vessels in the adjacent tissue (Fig. 2H). The area of inflammation was called leukomyelitis, inflammation of the white matter of the spinal cord, and it was surrounded by remarkable astroglial reaction with GFAP-posi- tive, enlarged, hypertrophied astrocytes in the band of tissue 100-150 $\mu \mathrm{M}$ thick surrounding the leukomyelitis (Fig. 2I-J).

In rats treated for 1 week with subdural infusion of $4 \mathrm{mg}$ dexamethasone, the cavity of the crush was directly connected to the subdural space (Fig. 3A) and contained many free, un-phagocytized red blood cells (Fig. 3B) and debris that were positive on the LFB stain (Fig. $3 \mathrm{C}$ ) and considered damaged myelin. There were rare phagocytic cells positive on the PAS stain and rare cells labelled positive with CD68 antibody scattered throughout (Fig. 3D-E). In the tissue surrounding the cavity of the crush, the GFAP stain revealed a band of astrogliosis, approximately 100-150 $\mu \mathrm{M}$ wide (Fig. 3F), with apparently increased numbers of markedly hypertrophied astrocytes (Fig. 3G).

In both dexamethasone-treated and un-treated rats in areas of the spinal cord at a distance, caudal to and separate from the lesion cavity, there were foci of haemorrhage in the dorsal column (Fig. 4A) surrounded by phagocytic cells with brown, finely granular material in the cytoplasm interpreted as haemosiderin (Fig. 4B). Although haemorrhages were not accompanied by loss of myelin (Fig. 3C), many scattered cells had PAS-positive cytoplasm (Fig. 4D), and there was astrogliosis in the surrounding tissue (Fig. 4E).
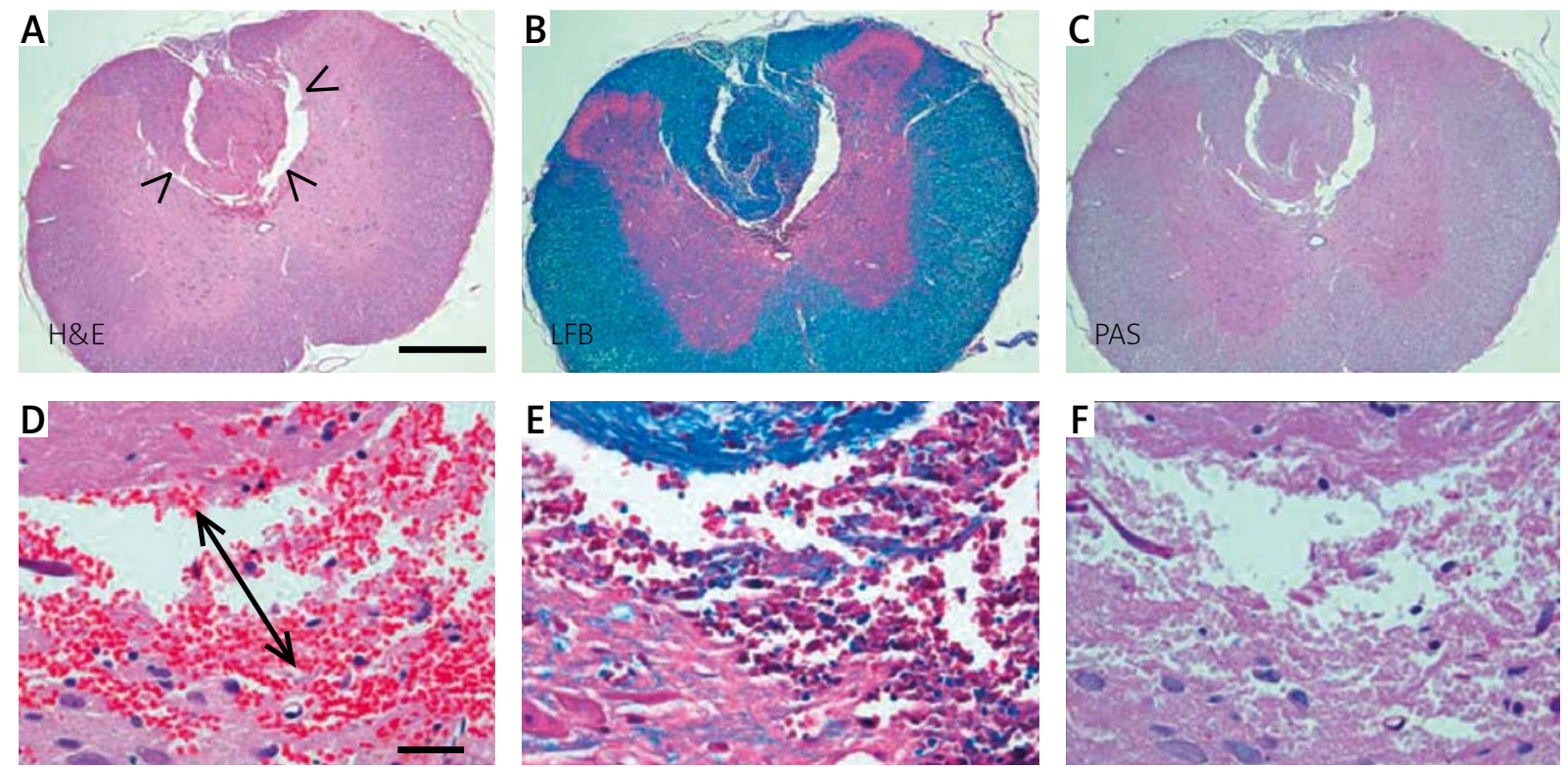

Fig. 1. Cross sections of the thoracic spinal cord from a rat with balloon crush injury perfused $2 \mathrm{~h}$ post-op. Large round area in the dorsal column appears separated from the surrounding tissue (arrowheads in A) and is surrounded by haemorrhages (D). Luxol fast blue (LFB) stain reveals tissue disruption around the dorsal column (B, E) but no evidence of myelin loss. Periodic acid-Schiff (PAS) stain reveals no active phagocytosis in the area of the disruption and haemorrhage (C, F). Bar $600 \mu \mathrm{m}-\mathrm{A}-\mathrm{C} ; 120 \mu \mathrm{m}-\mathrm{D}-\mathrm{F}$. 

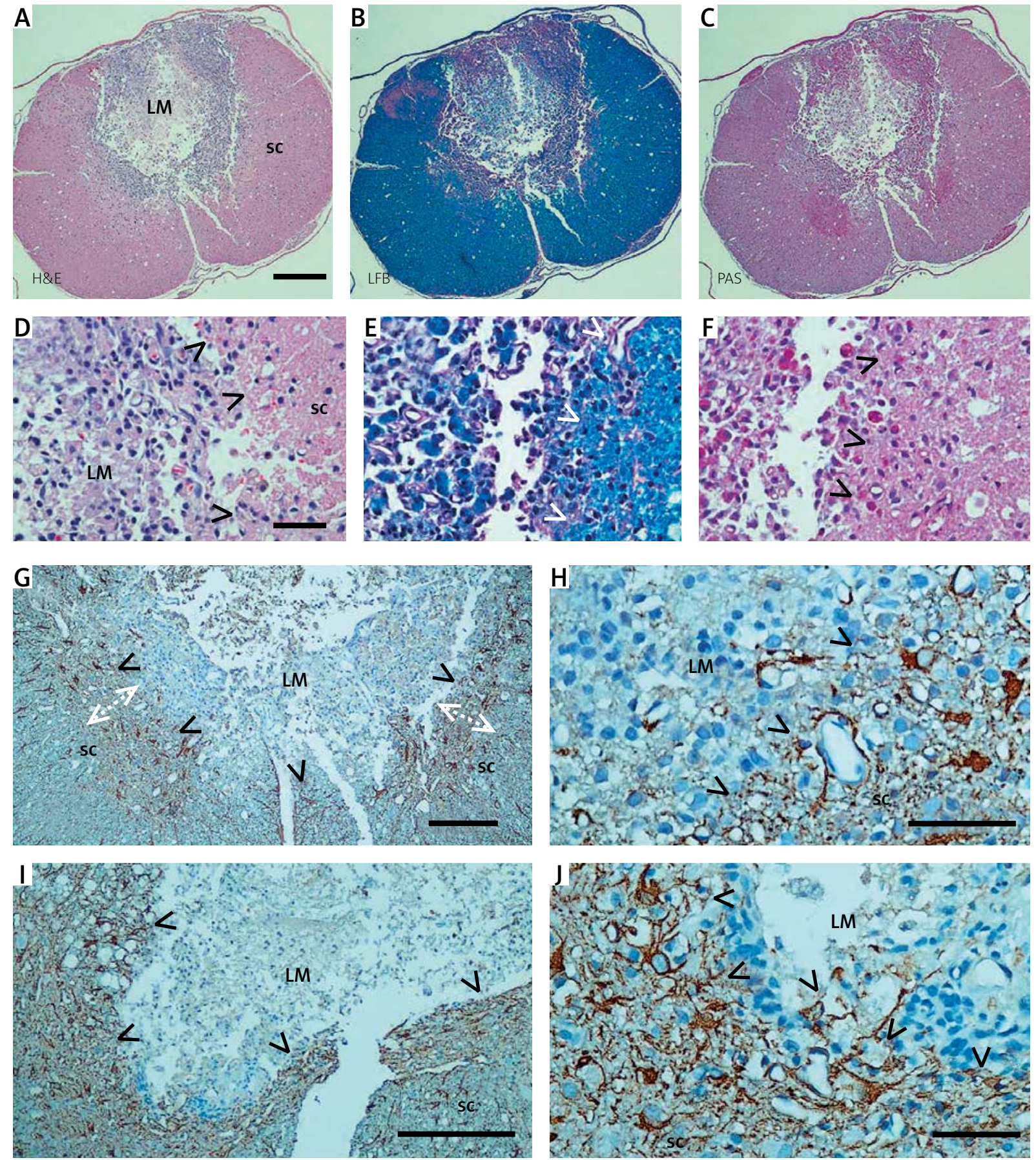

Fig. 2. Cross sections from the thoracic spinal cord 1 week after the balloon crush. The dorsal column is obliterated by leukomyelitis (LM) whose severe inflammatory infiltrate is delineated by arrowheads from the surrounding tissue of the spinal cord (sc) and is rich in macrophages that internalize LFB-positive myelin debris (E) and a large proportion of which are positive on PAS stain (F). A proportion of macrophages in the area of leukomyelitis are positive or weakly positive on anti-CD68 antibody staining (G), but there is strong positive staining of cells in the lumen of blood vessels in the adjacent tissue $(\mathbf{H})$ that are interpreted as monocytes. Band-like astrogliosis is evidenced by anti-GFAP antibody (I-J) in the tissue surrounding the cavity of the LM. Bars, A-C - $600 \mu \mathrm{M}$; D-H, J - $60 \mu \mathrm{M}$; I - $200 \mu \mathrm{M}$. 

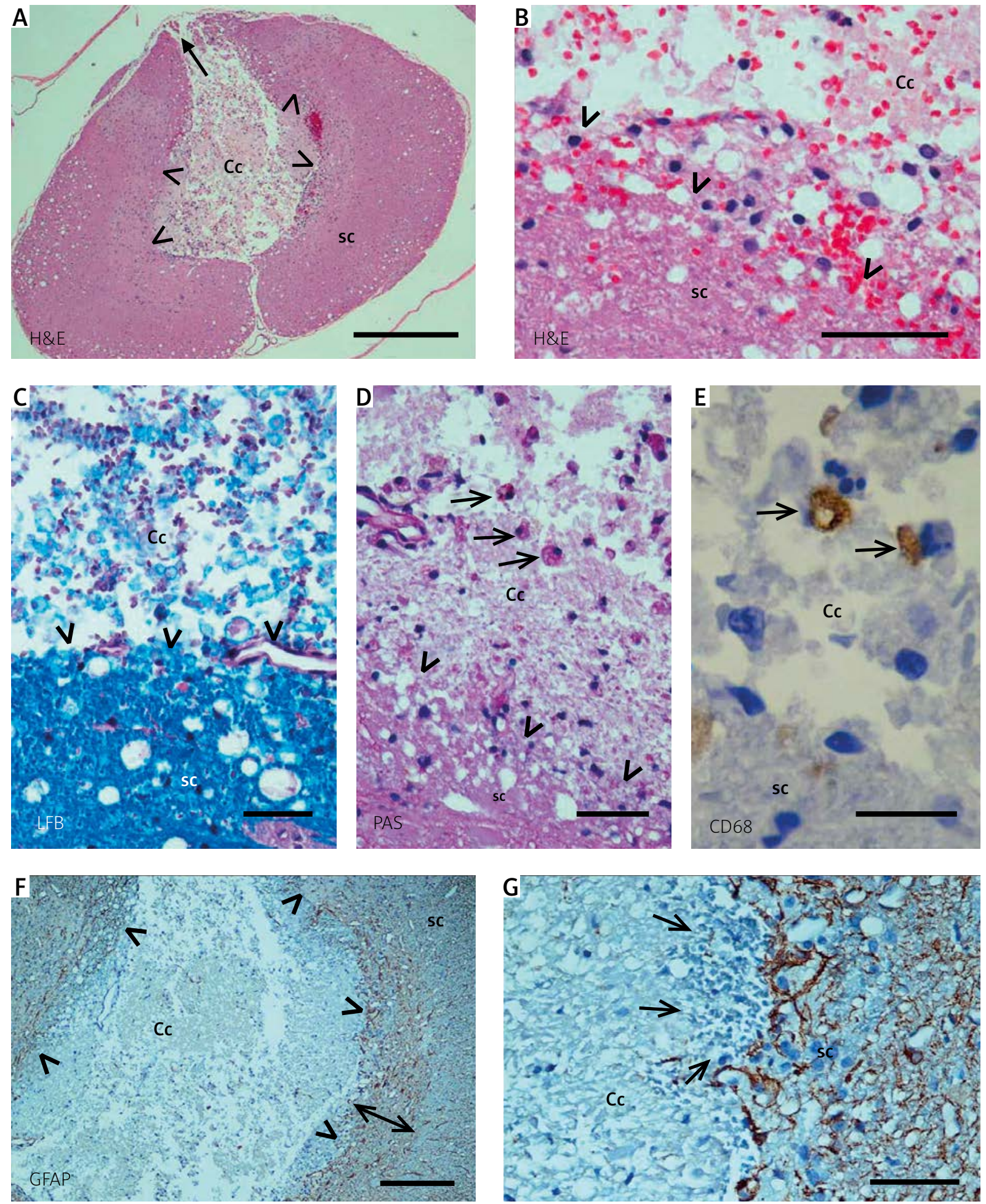

Fig. 3. The thoracic spinal cord 1 week after the crush, with $4 \mathrm{mg}$ dexamethasone infused throughout the post-op period subdurally in the vicinity of the crush lesion. The dorsal column is obliterated by the crush cavity (Cc) delineated by arrowheads, which apparently is connected with the subdural space (arrow in A) and contains scattered haemorrhages and proteinaceous material that stains positively with eosin on the $H \& E$ stain (A, B), and on the LFB stain (C), indicating widespread presence of damaged myelin that is not internalized by phagocytes. Scattered throughout there are rare individual PAS-positive cells (arrows in D) interpreted as macrophages. A proportion of cells scattered in the crush cavity stain positively with antiCD68 antibody (E). The tissue of the spinal cord surrounding the crush contains a band of astrogliosis evidenced by anti-GFAP antibody (double headed arrow in F, G). Bars, A-600 $\mu$ M; B-E, G - $60 \mu \mathrm{M} ; \mathrm{F}-200 \mu \mathrm{M}$. 

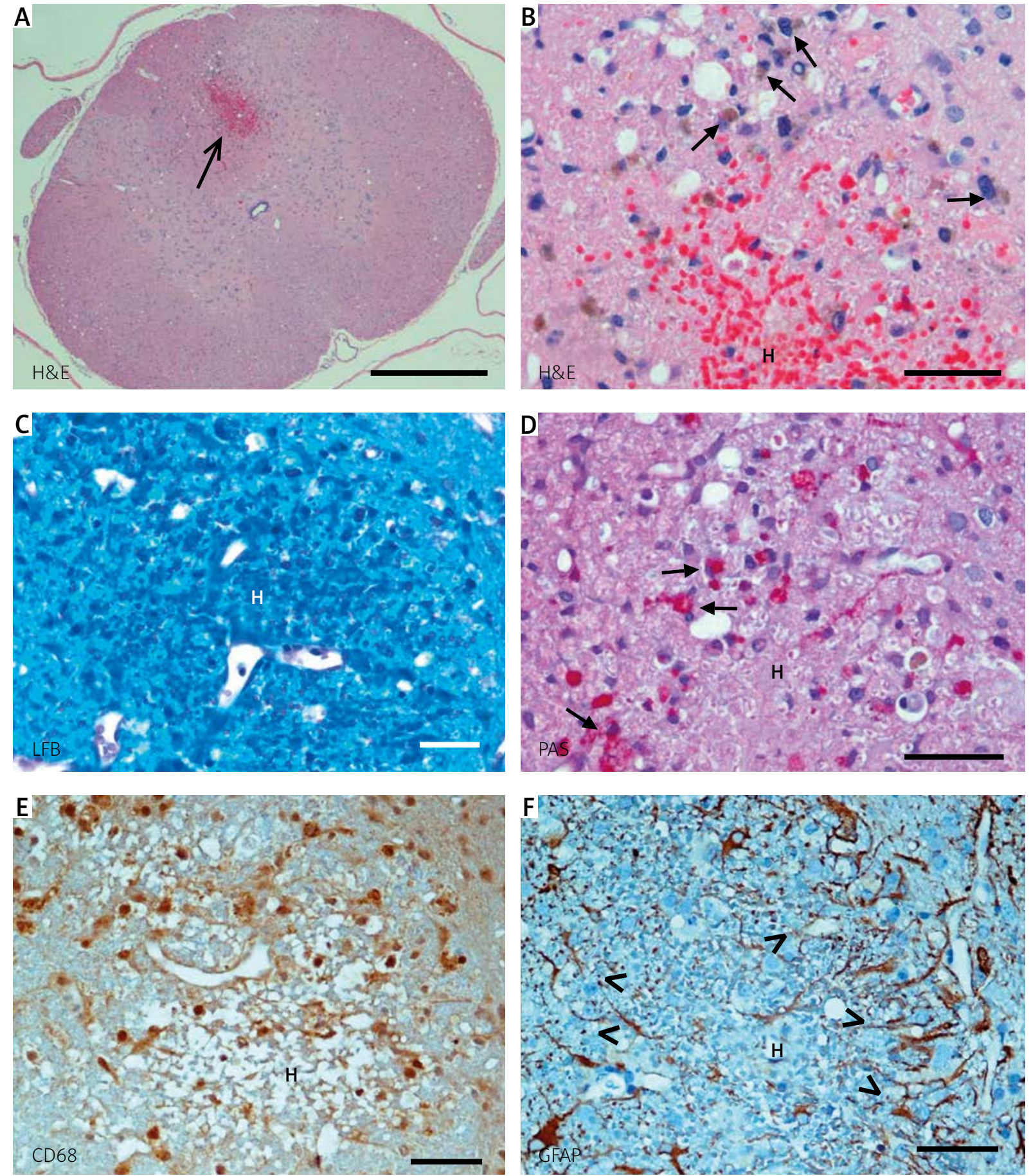

Fig. 4. In an untreated rat surviving the balloon crush for 1 week, the thoracic spinal cord at a distance from the crush lesion contains a large area of haemorrhage in the dorsal column, arrow in A. The haemorrhage is surrounded by scattered cells with elongated, sometimes subcleaved nucleus and finely granular brown material in the cytoplasm (small arrows in B). The phagocytic cells are interpreted as macrophages or microglia and the brown material as hemosiderin. The haemorrhage is not accompanied by loss of myelin (C). There are scattered cells with cytoplasm positive for PAS stain (D) that infiltrate the hemorrhagic area (H) that is delineated by arrowheads and surrounded by astrogliosis in E. Bars, A - $600 \mu \mathrm{M} ; \mathrm{B}-\mathrm{E}-60 \mu \mathrm{M}$. 
Histological analysis of extraneural tissues in rats treated with dexamethasone revealed remarkable organ pathology including splenic lymphoid atrophy, hepatic degeneration, kidney calcinosis, atrophying myopathy, colitis, degenerative changes in the islets of Langerhans in the pancreas and hemorrhagic cystitis. Analysis of extraneural tissues in the un-treated rats was not remarkable.

\section{Discussion}

In this study we successfully inhibited a severe phagocyte-rich inflammatory reaction to a spinal cord injury. Leukomyelitis, inflammation of the white matter in the spinal cord, was initiated by massive damage to the white matter in the dorsal column by means of crushing by an inflated catheter balloon placed epidurally. Subdural infusion of dexamethasone, a powerfully anti-inflammatory, stable, synthetic analogue of glucocorticoids, allowed for circumvention of the blood-brain barrier and apparently for achieving a sufficiently high concentration of this drug in the cerebrospinal fluid in proximity of the crush lesion to prevent severe, phagocyte-rich inflammation. Since the crush cavity was directly connected with the subdural space, it is considered that dexamethasone diffused from the subdural space into the crush cavity and thus inhibited massive infiltration by macrophages, therefore effectively arresting destruction of the neural tissue surrounding the cavity of the crush by the inflammatory process of leukomyelitis.

Although methylprednisolone has previously been used to treat spinal cord injury $[6,7]$, this drug is unstable in an aqueous solution beyond 24 hours, and in this study we used a more stable and 7 times more powerful [20] glucocorticoid analogue, dexamethasone. Anti-inflammatory activities of dexamethasone are powerful and multifactorial [20]. In vitro, dexamethasone can suppress phagocytosis by activation of murine peritoneal macrophages [4,5], which parallels reduction in the lysosomal secretion [22], with the reduced secretion of the lysosomal elastase [14], arachidonic acid [5], prostaglandins [10], thromboxane B2 and leukotriene B4 [21]. Dexamethasone inhibited the proliferation of macrophages after their activation by oxidized low-density lipoprotein, which coincided with the reduction in the levels of the granulocyte/macrophage colony stimulating factor in one study [52], and inhibited the differentiation of macrophages into multinucle- ated osteoclasts, bone-lysing cells, in another [46]. Other in vitro studies determined that a lipopolysaccharide-activated macrophage ability to kill mastocytoma tumours was inhibited by dexamethasone in parallel with the reduced glucose uptake by treated macrophages [44], the latter observation having been confirmed in another study [51]. Dexamethasone inhibits the toxicity of macrophages by reducing their nitric oxide production [36], and by related inhibition of inducible nitric oxide synthase [31]. In an in vivo study using a balloon injury of femoral arteries in the rabbit, daily administration of intramuscular $1 \mathrm{mg} / \mathrm{kg}$ b.w. dexamethasone resulted in a remarkable reduction of the macrophage accumulation in the wall of the damaged arteries coincident with the reduced expression of monocyte chemoattractant protein-1 [47]. This treatment did not, however, affect the levels of circulating monocytes, the adhesion of monocytes to the vascular endothelium or their ability to migrate [47], indicating that although anti-inflammatory activities of dexamethasone are powerful and multifactorial, there are a number of mechanisms of inflammation that this drug does not affect.

In our model of leukomyelitis, dexamethasone inhibited accumulation of macrophages in the cavity of the crush by mechanisms we did not investigate. In rats not treated with dexamethasone we observed widespread phagocytic activity of macrophages with the internalization of LFB-positive myelin debris. Free, LFB-positive, myelin material was not observed in the lesion cavity in the untreated rats. In contrast, large amounts of LFB-positive material remained free in the cavity of injury in the dexamethasone-treated rats, presumably because it was not removed by macrophage phagocytosis. Given the severity of the inflammatory response following the massive myelin damage in our model of the spinal cord injury and complete internalization of myelin debris by macrophages, the notion of severe pro-inflammatory activity of damaged myelin appears appropriate. Therefore, inhibiting its internalization by macrophage phagocytosis in dexamethasone-treated rats allowed us to postpone the onset of leukomyelitis for 1 week but not to eliminate it. Clearly, potent pro-inflammatory activity of non-phagocytized myelin debris in the crush lesion will need to be addressed in future studies where an effective but non-toxic anti-inflammatory treatment is administered for a longer period of time to $\mathrm{SCl}$ 
rats, allowing perhaps for elimination of damaged myelin by mechanisms not requiring phagocytosis with the associated tissue destruction.

Although the mouse anti-human CD68 antigen antibody used in this study labelled well intravascular monocytes in the neural tissue surrounding the cavity of injury, only a proportion of mononuclear cells in the cavity of injury were labelled. This antibody was selected due to its reliable labelling of macrophages in formalin-fixed and paraffin-embedded tissues [16]. Since a virtually uniform population of cells internalizing the LFB-positive material had a round to oval nucleus, and abundant, microvacuolated cytoplasm that often stained positive on the PAS reaction, we consider them macrophages and suggest that the patchy labelling with the anti-CD68 antibody may be indicative of dynamic changes in the surface epitopes of macrophages potently activated by damaged myelin.

The evidence of reactive astrogliosis in the spinal cord tissue surrounding the cavity of leukomyelitis is consistent with astrogliosis around stroke lesions $[2,38]$. Although the role of astrogliosis in progression of leukomyelitis is unknown, old lesions in the spinal cord, also known as syringomyelia, that are filled with clear cerebrospinal fluid and do not contain inflammatory cells, are invariably surrounded by a wall of hypertrophied astrocytic processes [26,35]. Interestingly, the high dose of dexamethasone used in this study did not appear to have an inhibitory effect on astrogliosis despite being potently inhibitory to phagocytosis.

Evidence of acute haemorrhages in areas isolated from the site of the injury is indicative of fragility of blood vessels of the spinal cord in post-traumatic rats. Although the precise mechanism of acute haemorrhages is unknown, it is important to emphasize that the movement of the rats was not restricted post-operatively and the potential for movement of the spinal cord remained. This observation may serve as supportive evidence for the need to immobilize the spine of the traumatized patients, apparently to prevent additional haemorrhages after the initial spinal cord injury.

\section{Acknowledgements}

We wish to thank Dr. H. Szechtman and M. Tucci for their help with the open field studies. This study was funded by the Medical University of Lublin, Poland.

\section{Disclosure}

The authors report no conflict of interest.

\section{References}

1. Anderson DK, Means ED, Waters TR, Green TS. Microvascular perfusion and metabolism in injured spinal cord after methylprednisolone treatment. J Neurosurg 1982; 56: 106-113.

2. Bailey EL, Smith C, Sudlow CLM, Wardlaw JM. Pathology of lacunar ischemic stroke in humans - a systematic review. Brain Pathol 2012; 22: 583-591.

3. Bao F, Dekaban GA, Weaver LC. Anti-CD11d antibody treatment reduces free radical formation and cell death in the injured spinal cord of rats. J Neurochem 2005; 94: 1361-1373.

4. Becker J, Grasso RJ. Suppression of phagocytosis by dexamethasone in macrophage cultures: inability of arachidonic acid, indomethacin, and nordihydroguaiaretic acid to reverse the inhibitory response mediated by a steroid-inducible factor. Int J Immunopharmacol 1985; 7: 839-847.

5. Becker JL, Grasso RJ, Davis JS. Dexamethasone action inhibits the release of arachidonic acid from phosphatidylcholine during the suppression of yeast phagocytosis in macrophage cultures. Biochem Biophys Res Commun 1988; 153: 583-590.

6. Bracken MB, Shepard MJ, Collins WF, Holford TR, Young W, Baskin DS, Eisenberg HN, Flamm E, Leo-Summers L, Maroon J, Marshall LF, Perot PL, Piepmeier J, Sonntag VKH, Wagner FC, Wilberger JE, Winn HR. A randomized, controlled trial of methylprednisolone or naloxone in the treatment of acute spinal-cord injury. N Eng J Med 1990; 322: 1405-1411.

7. Bracken MB. Steroids for acute spinal cord injury (Review). Cochrane Database Syst Rev 2012; 1: 1-51.

8. Braughler JM, Hall ED. Correlation of methylprednisolone levels in cat spinal cord with its effects on $\left(\mathrm{Na}^{+}+\mathrm{K}^{+}\right)$-ATPase, lipid peroxidation, and alpha motor neuron function. J Neurosurg 1982; 56: 838-844.

9. Braughler JM, Hall ED. Effects of multi-dose methylprednisolone sodium succinate on injured cat spinal cord neurofilament degradation and energy metabolism. J Neurosurg 1984; 61: 290-295.

10. Brune K, Kalin H, Rainsford KD, Wagner K. Dexamethasone inhibits the release of prostaglandins and the formation of autophagic vacuoles from stimulated macrophages. Adv Prostaglandin Thromboxane Res 1980; 8: 1679-1684.

11. Carlson SL, Parrish ME, Springer JE, Doty K, Dossett L. Acute inflammatory response in spinal cord following impact injury. Exp Neurol 1998; 151: 77-88.

12. Chang HT. Subacute spinal cord contusion: few lymphocytes and many macrophages. Spinal Cord 2007; 45: 174-182.

13. Chen H-C, Fong T-H, Lee A-W, Chi W-T. Autophagy is activated in injured neurons and inhibited by methylprednisolone after experimental spinal cord injury. Spine 2012; 37: 470-475.

14. Dahlgren ME, Davies P, Bonney RJ. Phorbol myristate acetate induces the secretion of an elastase by populations of resident and elicited mouse peritoneal macrophages. Biochim Biophys Acta 1980; 630: 338-351. 
15. Emmez H, Borcek AO, Kaymaz M, Kaymaz F, Durdag E, Civi S, Gulbahar O, Aykol S, Pasaoglu A. Neuroprotective effects of gabapentin in experimental spinal cord injury. World Neurosurg 2010; 73: 729-734.

16. Falini B, Flenghi L, Pileri S, Gambacorta M, Bigerna B, Durkop H, Eitelbach F, Thiele J, Pacini R, Cavaliere A, Martelli M, Cardarelli N, Sabattini E, Poggi S, Stein H. PG-M1: A new monoclona antibody directed against a fixative-resistant epitope on the macrophage-restricted form of the CD68 molecule. Am J Patho 1993; 142: 1359-1372.

17. Felleiter P, Muller N, Schumann F, Felix O, Lierz P. Changes in the use of methylprednisolone protocol for traumatic spinal cord injury in Switzerland. Spine 2012; 37: 953-956.

18. Fitch MT, Doller C, Combs CK, Landreth GE, Silver J. Cellular and molecular mechanisms of glial scarring and progressive cavitation: in vivo and in vitro analysis of inflammation-induced secondary injury after CNS trauma. J Neurosci 1999; 19: 8182-8198.

19. Fleming JC, Norenberg MD, Ramsay DA, Dekaban GA, Marcillo AE, Saenz AD, Pasquale-Styles M, Dietrich DD, Weaver LC. The cellular inflammatory response in human spinal cords after injury. Brain 2006; 129: 3249-3269.

20. Fraser CM, Mays A. Steroids. In: The Merck Veterinary Manual. $6^{\text {th }}$ ed. Fraser CM, Mays A (eds.). Merck \& CO., Inc., Rahway 1986; pp. 1592-1596.

21. Fuller RW, Kelsey CR, Cole PJ, Dollery CT, McDermott J. Dexamethasone inhibits the production of thromboxane B2 and leukotriene B4 by human alveolar and peritoneal macrophages. Clin Sci 1984; 67: 653-656.

22. Gewert K, Tapper H, Naucler C, Sundler R. Dexamethasone downregulates lysosomal secretion in mouse macrophages: involvement of signalling through protein kinase C. J Inflamm 1996; 47 115-125.

23. Gul S, Hanci V, Bahadir B, Acikgoz S, Baktas S, Ankarali H, Kalayci M, Acikgoz B. The effectiveness of dexmedetomidine in experimental spinal cord injury compared to methylprednisolone in rats. J Clin Neurosci 2010; 17: 490-494.

24. Ha K-Y, Carragee E, Cheng Y, Kwon S-E, Kim Y-H. Pregabalin as a neuroprotector after spinal cord injury in rats: biochemical analysis and effect on glial cells. J Korean Med Sci 2011; 26 : 404-411.

25. Hanci V, Kerimoglu A, Koca K, Baskesen A, Kilic K, Tastekin D. The biochemical effectiveness of $\mathrm{N}$-acetylcysteine in experimental spinal cord injury in rats. Turkish J Trauma Emerg Surg 2010; 16: 15-21.

26. Horenstein S. Intramedullary cyst formation with progressive gliosis (traumatic syringomyelia) following spinal cord injury. Trans Am Neurol Assoc 1970; 95: 263-266.

27. Hughes JT. Disorders of the spine and spinal cord. In: Greenfield's Neuropathology. $5^{\text {th }}$ ed. Adams JH, Duchen LW (eds.). Oxford University Press, New York 1992; pp. 1083-1115.

28. Kavakli HS, Koca C, Alici O. Antioxidant effects of curcumin in spinal cord injury in rats. Turk J Trauma Surg 2011; 17: 14-18.

29. Kigerl KA, McGaughy VM, Popovich PG. Comparative analysis of lesion development and intraspinal inflammation in four strains of mice following spinal contusion injury. J Comp Neurol 2006; 494: 578-594.
30. Kigerl KA, Gensel JC, Ankeny DP, Alexander JK, Donnelly DJ, Popovich PG. Identification of two distinct macrophage subsets with divergent effects causing either neurotoxicity or neuroregeneration in the injured mouse spinal cord. J Neurosci 2009; 29: 13435-13444.

31. Korhonen R, Lahti A, Hamalainen M, Kankaanranta H, Moilanen $\mathrm{E}$. Dexamethasone inhibits inducible nitric-oxide synthase expression and nitric oxide production by destabilizing mRNA in lipopolysaccharide-treated macrophages. Mol Pharmacol 2002; 62: 698-704.

32. Kose EA, Bakar B, Ayva SK, Kilinc K, Apan A. Neuroprotective effects of racemic ketamine and (S)-ketamine on spinal cord injury in rat. Injury Int J Care Inj 2012; 43: 1124-1130.

33. Kwiecien JM. Cellular mechanisms of white matter regeneration in an adult dysmyelinated rat model. Folia Neuropathol 2013; 51: 189-202.

34. Kwiecien JM, Blanco M, Fox JG, Delaney KH, Fletch AL. Neuropathology of bouncer Long Evans, a novel dysmyelinated rat. Comp Med 2000; 50: 503-510.

35. Levine DN. The pathogenesis of syringomyelia associated with lesions at the foramen magnum: a critical review of existing theories and proposal of a new hypothesis. J Neurol Sci 2004; 220: 3-21.

36. Li Y, Ito N, Suzuki T, Stechschulte DJ, Dileepan KN. Dexamethasone inhibits nitric oxide-mediated toxicity via effects on both macrophages and target cells. Immunopharmacol 1995; 30: 177-186.

37. Lin H-S, Ji Z-S, Zheng L-H, Guo G-Q, Chen B, Wu H, Zhang G-W. Effect of methylprednisolone on the activities of caspase-3, - 6 , -8 , and -9 in rabbits with acute spinal cord injury. Exp Ther Med 2012; 4: 49-54.

38. Mancardi GL, Romagnoli P, Tassinari T, Gandolfo C, Primavera JM, Loeb C. Lacunae and cribriform cavities of the brain. Eur Neurol 1988; 28: 11-17.

39. Mantovani A, Sica A, Sozzani S, Allavena P, Vecchi A, Locati M. The chemokine system in diverse forms of macrophage activation and polarization. Trends Immunol 2004; 25: 677-686.

40. Markandaja M, Sten DM, Menaker J. Acute treatment options for spinal cord injury. Curr Treatment Options Neurol 2012; 14: 175-187.

41. Meng B, Zhang Q, Huang C, Zhanh HT, Tang T, Yang HL. Effects of a single dose of methylprednisolone versus three doses of rosiglitazone on nerve growth factor levels after spinal cord injury. J Int Med Res 2011; S39: 805-814.

42. Ning N, Dang X, Bai C, Zhang C, Wang K. Panax notoginsenoside produces neuroprotective effects in rat model of acute spinal cord ischemia-reperfusion injury. J Ethnopharmacol 2012; 139: 504-512.

43. Park S-J, Oh I-S, Kwon J-Y, Ha K-Y. The effect of irradiation and methylprednisolone in spinal cord injured rats. Spine 2011; 36: 434-440.

44. Perret G, Lemaire G. Dexamethasone inhibits antitumor potential of activated macrophages by a receptor mediated action. Biochem Biophys Res Commun 1986; 136: 130-136.

45. Pettiford JN, Bikhchandani J, Ostlie BJ, St. Peter SD, Sharp RJ, Juang D. A review: the role of high dose methylprednisolone in 
spinal cord trauma in children. Pediatr Surg Int 2012; 28: 287 294.

46. Pharoah MJ, Heersche JMN. Dexamethasone inhibits formation of osteoclast-like cells in bone marrow cultures. J Dent Res 1986; 65: 1006-1009.

47. Poon M, Gertz SD, Fallon JT, Wiegman P, Berman JW, Sarembock IJ, Taubman MB. Dexamethasone inhibits macrophage accumulation after balloon arterial injury in cholesterol fed rabbits. Atherosclerosis 2001; 155: 371-380.

48. Popovich PG, Guan Z, Wei P, Huitinga I, van Rooijen N, Stokes BT. Depletion of hematogenous macrophages promotes partial hindlimb recovery and neuroanatomical repair after experimental spinal cord injury. Exp Neurol 1999; 158: 351-365.

49. Popovich PG, Hickey WF. Bone marrow chimeric rats reveal the unique distribution of resident and recruited macrophages in the contused rat spinal cord. J Neuropathol Exp Neurol 2001; 60: 676-685.

50. Popovich PG, Wei P, Stokes BT. Cellular inflammatory response after spinal cord injury in Sprague-Dawley and Lewis rats. J Comp Neurol 1997; 377: 443-464.

51. Rist RJ, Naftalin RJ. Dexamethasone inhibits the hexose monophosphate shunt in activated rat peritoneal macrophages by reducing hexokinase-dependent sugar uptake. Biochem J 1991; 278: $129-135$

52. Sakai M, Biwa T, Matsumura T, Takemura, T, Matsuda H, Anami Y, Sasahara T, Kobori S, Shichiri M. Glucocorticoid inhibits oxidized LDL-induced macrophage growth by suppressing the expression of granulocyte/macrophage colony-stimulating factor. Artheroscler Thromb Vasc Biol 1999; 19: 1726-1733.

53. Sanli AM, Serbes G, Caliskan M, Kaptanoglu E, Sargon MF, Kilinc K, Besalti O, Sekerci Z. Effect of granulocyte-colony stimulating factor on spinal cord tissue after experimental contusion injury. J Clin Neurosci 2010; 17: 1548-1552.

54. Sanli AM, Serbes G, Sargon MF, Caliskan M, Kilinc K, Bulut H, Sekerci Z. Mathothrexate attenuates early neutrophil infiltration and the associated lipid peroxidation in the injured spinal cord but does not induce neurotoxicity in the injured spinal cord in rats. Acta Neurochirurg 2012; 154: 1045-1054.

55. Sanli AM, Turkoglu E, Serbes G, Sargon MF, Besalti O, Kilinc K, Irak A, Sekerci Z. Effect of curcumin on lipid peroxidation, early ultrastructural findings and neurological recovery after experimental spinal cord contusion injury in rats. Turk Neurosurg 2012; 22: 189-195.

56. Satake K, Matsuyama Y, Kamyia M, Kawakami H, Iwata H, Adachi K, Kiuchi K. Nitric oxide via macrophage iNOS induces apoptosis following traumatic spinal cord injury. Mol Brain Res 2000; 85: 114-122.

57. Schnell L, Fearn S, Klassen H, Schwab ME, Perry VH. Acute inflammatory responses to inflammatory lesions in the CNS: differences between brain and spinal cord. Eur J Neurosci 1999; 11: 3648 3658.

58. Schwab JM, Brechtel K, Mueller CA, Failli V, Tuli SK, Schluesener HJ. Experimental strategies to promote spinal cord regeneration - an integrative perspective. Prog Neurobiol 2006; 78: 91-116.

59. Slausson DO, Cooper BJ. Pathology - the study of disease. W: Mechanisms of Disease: A Textbook of Comparative Gener- al Pathology. Salusson DO, Cooper BJ (eds.). Williams \& Wilkins, Baltimore 1990; pp. 1-18.

60. Soriano SG, Amaravadi LS, Wang YF, Zhou H, Yu GX, Tonra JR, Fairchild-Huntress V, Fang Q, Dunmore JH, Huszhar D, Pan Y. Mice deficient in fractalkine are less susceptible to cerebral ischemia-reperfusion injury. J Neuroimmunol 2002; 125: 59-65.

61. Vanicky I, Urdzikova L, Saganova L, Cizkova D, Galik J. A simple and reproducible model of spinal cord injury induced by epidural balloon inflation in the rat. J Neurotrauma 2001; 18: 1399-1407.

62. Vanicky I, Urdzikova L, Saganova K, Marsala M. Intrathecal methylprednisolone does not improve outcome after severe spinal cord injury in the rat. Neurosci Res Commun 2002; 31: 183-191.

63. Xiong M, Chen S, Yu H, Liu Z, Zeng Y, Li F. Neuroprotection of erythropoietin and methylprednisolone against spinal cord ischemia-reperfusion injury. J Huazhong Univ Sci Technol 2011; 31: 652-656

64. Yilmaz ER, Kertmen H, Dolgun H, Gurer B, Sanli AM, Kanat MA, Arikok AT, Bahsi SY, Erguder BE, Sekerci Z. Effects of darbepoietin-alpha in spinal cord ischemia-reperfusion injury in the rabbit. Acta Neurochir 2012; 154: 1037-1044. 